\title{
Immunoglobulin G Subclass 2 Measurement
}

National Cancer Institute

\section{Source}

National Cancer Institute. Immunoglobulin G Subclass 2 Measurement. NCI Thesaurus.

Code C122128.

The determination of the amount of immunoglobulin G subclass 2 present in a sample. 